RESEARCH PAPER

\title{
Higher cigarette prices influence cigarette purchase patterns
}

\author{
A Hyland, J E Bauer, Q Li, S M Abrams, C Higbee, L Peppone, K M Cummings
}

Tobacco Control 2005;14:86-92. doi: 10.1136/tc.2004.008730

\begin{abstract}
See end of article for authors' affiliations ......................

Correspondence to: K Michael Cummings, $\mathrm{PhD}, \mathrm{MPH}$, Roswell Park Cancer Institute, Department of Health Behavior, Elm and Carlton Streets, Buffalo, New York 14263, USA: michael.cummings@ roswellpark.org
\end{abstract}

Received 5 May 2004 Accepted 28 October 2004

\begin{abstract}
Objective: To examine cigarette purchasing patterns of current smokers and to determine the effects of cigarette price on use of cheaper sources, discount/generic cigarettes, and coupons.

Background: Higher cigarette prices result in decreased cigarette consumption, but price sensitive smokers may seek lower priced or tax-free cigarette sources, especially if they are readily available. This price avoidance behaviour costs states excise tax money and dampens the health impact of higher cigarette prices.

Methods: Telephone survey data from 3602 US smokers who were originally in the COMMIT (community intervention trial for smoking cessation) study were analysed to assess cigarette purchase patterns, use of discount/generic cigarettes, and use of coupons.

Results: $59 \%$ reported engaging in a high price avoidance strategy, including $34 \%$ who regularly purchase from a low or untaxed venue, $28 \%$ who smoke a discount/generic cigarette brand, and $18 \%$ who report using cigarette coupons more frequently that they did five years ago. The report of engaging in a price avoidance strategy was associated with living within $\mathbf{4 0}$ miles of a state or Indian reservation with lower cigarette excise taxes, higher average cigarette consumption, white, non-Hispanic race/ethnicity, and female sex.

Conclusion: Data from this study indicate that most smokers are price sensitive and seek out measures to purchase less expensive cigarettes, which may decrease future cessation efforts.
\end{abstract}

$\mathrm{n}$ recent years, the federal cigarette excise tax has increased and the majority of states have also increased cigarette excise taxes, resulting in increases in cigarette prices. ${ }^{1}$ Industry initiated price increases since the Master Settlement Agreement in 1998 have raised cigarette prices even more than the excise tax increases. ${ }^{1}$ Higher cigarette prices result in a decrease in cigarette consumption ${ }^{23}$; however, the evidence shows that many price sensitive smokers switch to discount cigarette brands when prices increase. ${ }^{4}$ Therefore, the higher cigarette prices observed recently may not exert the expected effect on cigarette consumption.

Those who do not switch to discount cigarette brands may try to find sources of cheaper cigarettes or use discount coupons. The combination of a wide range in cigarette prices and the emergence of the internet and other readily available sources to purchase cheaper cigarettes and to obtain discount coupons has created unprecedented opportunities for smokers to purchase lower taxed and lower priced cigarettes, which costs the state money and decreases the health impact of the excise tax increases. Previous research shows that smokers who switch to discount brands are less likely to quit, ${ }^{4}$ and it is possible that a similar decrease in cessation will occur among those who seek out lower priced cigarette alternatives.

Several studies have assessed the impact of cigarette smuggling on cigarettes sales and smoking behaviour. Most of the previous studies used the legal sale data and cigarette demand information to estimate the extent of smuggling. For example, a widely used approach is to determine how demographic factors and differences in tax rates relative to other states affect aggregate level cigarette sales and the estimated consumption is compared to actual consumption to determine the impact of tax differentials. ${ }^{5-7}$ Yurekli and Zhang found that in 1995 the net revenue lost by states because of smuggling was $\$ 317$ million ( $\sim 6 \%$ of the states' tax revenues). ${ }^{8}$ Several have controlled for cross border smuggling, and the findings indicated that price elasticity estimates still fell into a range of -0.4 to $-0.6,{ }^{68}$ which is comparable with past estimates. Merriman concluded that the tendency of cigarette taxes to deter smoking is not diminished by smuggling. ${ }^{9}$ One of the disadvantages of these studies is that few have relied on individual level data that assesses actual purchase patterns, which may vary widely within a population, and changes in smoking behaviour in relation to price differentials.

Examples of studies that have relied on individual level data include a 1999 survey of California adult smokers which indicated that $5.1 \%$ of smokers reported usually purchasing cigarettes from lower or non-taxed venues, including the internet, military bases, or out-of-state vendors. ${ }^{3}$ While only $0.3 \%$ avoided the excise tax by usually purchasing cigarettes on the internet, this source is becoming more widely utilised. Other lower or no tax sources for cigarettes are also becoming more popular. A second example is a New Jersey study between 2000 and 2002 that found the rate smokers reporting they usually purchase cigarette on the internet increased by threefold after a 70 cent cigarette excise tax increase..$^{10}$ In contrast to the relatively lower reported levels of smokers seeking out low or untaxed cigarettes, a recent survey of western New York adult smokers in 2002-2003 found that $67 \%$ of smokers reported that they usually purchase their cigarettes from an Indian reservation, where the average cigarette price was $40 \%$ that of an off reservation convenience store. ${ }^{11}$ These data confirm that the prevalence of tax avoidance behaviour varies considerably in the population.

Only two studies exist that examine the correlates of use of discount or generic cigarettes, which use data collected in the late 1980s and early 1990s. Both found that lower incomes and greater daily cigarette consumption to be strongly associated with the use of discount and generic cigarettes. ${ }^{4}{ }^{12}$ One study correlated changes in cigarette prices with the use of discount and generic cigarettes and found a strong, inverse association-those who smoked a discount brand at baseline were $21 \%$ less likely to quit smoking five years later, after 
adjusting for amount smoked and socio-demographic factors, compared to those who smoked full priced brands at baseline. ${ }^{4}$ We are aware of no studies that examine how discount coupons are used by consumers and their relationship with indicators of cessation.

When taxes are increased, a variety of purchase outcomes could theoretically occur for those who continue to smoke. Premium brand smokers could switch to generic cigarettes or they could purchase cigarettes from lower taxed sources (for example, another state, the internet). Generic brand smokers could purchase cigarettes from lower taxed sources, which could be a premium or generic brand depending on the price differential (for example, their generic brand in their home state may cost as much as a premium brand in a neighbouring state with lower taxes, so premium brand selection could actually increase in this group).

Many econometric studies of the impact of higher cigarette prices on smoking behaviour were conducted before lower priced purchase options were widespread and more recent studies have typically relied on aggregate data, which may miss segments of the population that have greater accessibility to lower priced sources. For example, the first econometric studies to assess the role of cigarettes excise taxes on smoking prevalence took place in the early 1980s, ${ }^{13}{ }^{14}$ before widespread availability of discount cigarettes, the internet, and low priced Indian reservation cigarettes. Today, when cigarette excise taxes increase, price sensitive consumers have more choices to purchase lower priced products and continue to smoke rather than quit, as some would have done without such purchase options. Failure to account for the increased availability of lower priced purchase alternatives may yield a biased estimate of the price elasticity for smoking cessation, initiation, and consumption, but the direction of the bias depends on the data being used to estimate price elasticity.

As more states increase cigarette excise taxes and tobacco companies continually market a wide array of discount and generic brands and offer record level of promotional allowances that effectively reduce the price of cigarettes, there is an increasing need to understand better how consumers alter their purchase patterns to respond to price increases. The goals of this paper are to examine the cigarette purchasing patterns of a large sample of smokers from 20 US communities and to examine correlates of the report of less expensive cigarette purchases.

\section{METHODS}

\section{The original COMMIT study}

One of the first efforts to evaluate the effect of a communitybased tobacco control intervention was the National Cancer Institute's evaluation of the community intervention trial for smoking cessation (COMMIT). Details of the COMMIT intervention are given below and are also published elsewhere. $^{15}{ }^{16}$ Briefly, COMMIT was the largest randomised community based cessation study ever conducted and the goal was that a multi-faceted intervention implemented between 1988 and 1993 would increase cessation in smokers age 25-64 years of age in communities that received the intervention, particularly for those who smoked 25 or more cigarettes per day. COMMIT featured 11 matched pairs of communities in the US ( 10 pairs) and Canada (one pair). Results showed that the COMMIT intervention implemented over a four year period increased quit rates by $3 \%$ for light-tomoderate smokers, but had no impact on quit rates among heavy smokers. ${ }^{17}$

The COMMIT cohort was identified by a telephone survey in 1988. Only current smokers aged 25-64 years were eligible. The first stage of the survey identified a representative sample of 5400 households within each community to gather information on the age, sex, and smoking patterns of all adults within selected households (response rate $84 \%$ ). In the second stage, a random sample of current smokers aged 2564 years was selected for an extended interview that included questions about current and past smoking behaviours, brand and type of cigarette usually smoked, interest in quitting smoking, etc (response rate 92\%). Attempts were made to assess the smoking status of all of those initially identified in 1988. Over the study period, $34 \%$ of the baseline smokers were lost to follow up (29\% unable to locate, $2 \%$ death, $3 \%$ other reasons) or about $8 \%$ per year.

\section{1 follow up survey of original COMMIT cohort participants}

A follow up telephone survey was conducted in the summer of 2001 with all of the US subjects who had completed the 1993 interview at the conclusion of the COMMIT study to assess changes in their smoking behaviour. Among the 12435 baseline smokers who resided in the USA interviewed in 1993 and agreed to be recontacted in the future, 6603 (53\%) were successfully re-interviewed in 2001 resulting in an $8 \%$ attrition rate per year, which is similar to the attrition rate observed between 1988 and 1993. Comparing responders and non-responders revealed that factors that might be associated with predictors of smoking status such as cigarettes per day, past quit attempts, and living with another smoker were not associated with being lost to follow up. Persons who were male, younger, non-white, less educated, no desire to quit, and smoked their first cigarette within 10 minutes after waking were more likely to be lost to follow up between 1988 and 2001. Compared to the mean response rate for all communities, those who lived in Hayward and Vallejo (California), Lowell (Massachusetts), Patterson and Trenton (New Jersey), and Yonkers (New York) were more likely to be lost to follow up, while those who lived in Cedar Rapids and Davenport (Iowa), Binghamton (New York), Raleigh (North Carolina), and Bellingham and Longview (Washington) were less likely to be lost to follow up. A total of 3602 subjects were classified as currently smoking on some days or everyday in the 2001 survey and also lived in the same state in 1988 and 2001, and this group is used for the analyses presented. For our analysis of patterns of discount/ generic cigarette use, we used data from the 5225 subjects who were smokers in 1988, completed the 1993 and 2001 longitudinal surveys, and had a known pricing tier for their reported cigarette brand.

Independent variables: measures of cigarette price The current state cigarette excise tax at the time of the survey was obtained from the STATE system created by the Office on

Table 1 List of premium and discount/generic brands

Premium American, American Spirit, Barclay, Belair, Benson \& Hedges, Camel, Capri, Carlton, Century, Chesterfield, Commander, Eve, Gitanes, Kent, Kool, L \& M, Lark Lucky Strike, Marlboro, Max, Merit, More, Nat Sherman, Newport, Now, Pall Mall, Parliament, Philip Morris, Players, Raleigh, Rothman, Salem, Saratoga, Satin, Tareyłon, True, Vantage, Virginia Slims, Winston

Discount/ Austin, Bailey, Basic, Best Buy, Best Value, Bonus Value, generic Bronco, Bronsen, Bucks, Cambridge, Carnival, Cimarron, CT, Doral, Exact, Export, Generic, GPC, Gunsmoke, Hi Val, Lewiston, Liggett, Magna, Malibu, Market, Maverick, Misty, Monarch, Money, Montclair, Native, Old, Prime, Private Stock, Pyramid, Rainbow, Roger, Senecas, Shield, Sincerely Yours, Smokin Joes, Sundance, USA Gold, Value Buy, Value Pride, Viceroy, Wave, Westport, Yours 
Smoking and Health at the Centers for Disease Control and Prevention to perform surveillance of tobacco related policies and behaviours. ${ }^{18}$ These data were used to create a price differential variable that is equal to the state excise tax minus the excise tax of a nearby state, Indian reservation, or Mexico within 40 miles of roadway. Negative differentials were set equal to zero (that is, the differential is zero if nearby states have higher cigarette excise taxes). Only those states within 40 miles of a lower taxed source had a positive price differential assigned to it. Categories used were 1-15 cents, 16-76 cents, and 77+ cents. The locations of Indian reservations in the USA were determined using maps found on the National Parks Service website (http://www.cr. nps.gov/nagpra/DOCUMENTS/ResMAP.HTM). The distances from the communities to other states, Mexico, and Indian reservations were then calculated using the Rand McNally road atlas of the USA, Canada, and Mexico, 1998 version. Four communities were within 40 miles of two lower taxed locations, in which case the closest source was used for determining the price differential.

\section{Dependent variables: measures of purchasing cigarettes from less expensive venues}

In the 2001 survey, current smokers answered a battery of questions concerning their cigarette purchasing patterns in the 12 months before the survey, including whether or not they have "regularly purchased cigarettes" from each of the following venues in the past 12 months "because they were cheaper": (1) on an Indian reservation; (2) in another state; and (3) in another country. Querying if the respondent made

\begin{tabular}{|c|c|c|}
\hline & $\mathbf{n}$ & $\%$ \\
\hline \multicolumn{3}{|l|}{ Sex } \\
\hline Male & 1681 & 47 \\
\hline Female & 1921 & 53 \\
\hline \multicolumn{3}{|l|}{ Age in 1988} \\
\hline $25-34$ years & 1218 & 34 \\
\hline $35-44$ years & 1278 & 35 \\
\hline $45-54$ years & 711 & 20 \\
\hline $55-64$ years & 395 & 11 \\
\hline \multicolumn{3}{|l|}{ Race } \\
\hline White, non-Hispanic & 3144 & 87 \\
\hline Black, non-Hispanic & 204 & 6 \\
\hline Hispanic & 177 & 5 \\
\hline Other & 76 & 2 \\
\hline \multicolumn{3}{|l|}{ Income in 2001} \\
\hline$<\$ 15000$ & 257 & 8 \\
\hline$\$ 15000-\$ 37500$ & 811 & 24 \\
\hline$\$ 37501-\$ 60000$ & 1089 & 32 \\
\hline$>\$ 60000$ & 1197 & 36 \\
\hline \multicolumn{3}{|c|}{ Number of cigarettes per day (2001) } \\
\hline$<5$ & 328 & 9 \\
\hline $5-14$ & 912 & 25 \\
\hline $15-24$ & 1530 & 43 \\
\hline $25-34$ & 475 & 13 \\
\hline$\geqslant 35$ & 345 & 10 \\
\hline \multicolumn{3}{|l|}{ Desire to quit (2001) } \\
\hline Not at all & 349 & 11 \\
\hline A little & 444 & 14 \\
\hline Somewhat & 1120 & 34 \\
\hline A lot & 1337 & 41 \\
\hline \multicolumn{3}{|c|}{ Number of past quit attempts } \\
\hline 0 & 1096 & 31 \\
\hline 1 & 721 & 20 \\
\hline $2+$ & 1739 & 49 \\
\hline \multicolumn{3}{|c|}{ Time to first cigarette (2001) } \\
\hline$<10$ mins & 1069 & 30 \\
\hline $10-30$ mins & 1263 & 35 \\
\hline $31-60$ mins & 622 & 17 \\
\hline $61+$ mins & 623 & 17 \\
\hline
\end{tabular}

any cigarette purchase on the internet in the 12 months before the interview "because they were cheaper" assessed internet purchasing. These four measures were also combined into a summary measure that is equal to 1 if the respondent responds affirmatively to any of these four items and is equal to zero otherwise. These measures were unavailable in previous surveys of the COMMIT cohort.

\section{Dependent variables: use of discount/generic cigarettes and use of discount coupons}

Current smokers were considered to be smoking a discount/ generic cigarette brand if they self reported their brand as a "generic" brand or if, based on brand characteristics data and UPC code, they could be identified as a discounted brand based on data from the Maxwell Consumer Report. ${ }^{19}$ A small percentage of brands were classified as a discount/generic brand through subsequent web searches of internet based cigarette vendors. The list of brands classified as "premium" and "discount/generic" from the 2001 survey is given in table 1 .

In the 2001 survey, current smokers were asked the following question: "Do you use coupons to purchase cigarettes more frequently now than five years ago?" Subjects who responded "yes" were classified as having used coupons and all others were classified as not having used coupons.

\section{Other control variables}

The following additional variables were considered when examining correlates of purchasing cigarettes from less expensive sources:

- sex (male or female)

- age in 1988 (25-34 years, 35-44 years, 45-54 years, 55-64 years)

- race/ethnicity (white, non-Hispanic; black, non-Hispanic; Hispanic; other)

- gross household income in $2001(<\$ 15000 /$ year, \$15 000 to \$37 500/year, \$37 501 to \$60 000/year, > \$60 000/year)

- cigarettes smoked per day in $2001(<5,5-14,15-24,25-$ $34,35+)$

- time to first cigarette in the morning in $2001 \quad(<10$ minutes, 10-30 minutes, 31-60 minutes, $>60$ minutes)

- desire to stop smoking in 2001 (none, a little, somewhat, a lot)

- history of past serious quit attempts in 2001 (0 attempts, 1 attempts, $>2+$ attempts)

- pricing tier of cigarette smoked in 1993 (premium, discount/generic).

\section{Analyses}

Descriptive statistics were used to assess the characteristics of the sample and the prevalence of different alternative venues for cigarette purchasing, use of discount/generic cigarettes, and use of discount coupons. A multivariate logistic regression model was estimated to assess the characteristics of persons who engage in each of these discounted purchasing activities.

\section{RESULTS}

The characteristics of the 2001 sample of smokers are described in table 2. Because the cohort initially sampled heavier smokers between the ages of 25-64 years in 1988, respondents to the 2001 survey tended to be older and heavier smokers compared to national smoker data from the 1998/9 Current Population Survey Tobacco Use Supplement (data not shown). 


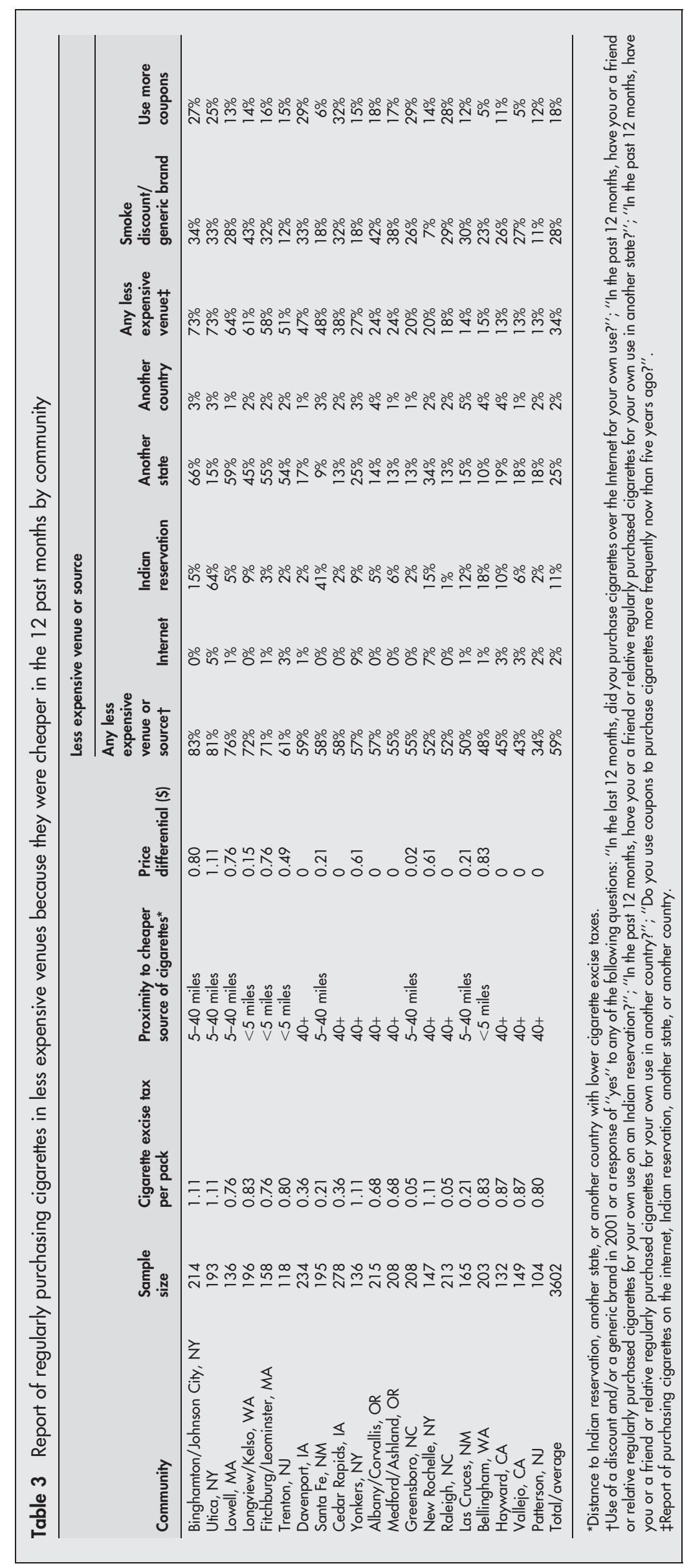


Table 4 Characteristics of those who reported purchasing cigarettes from a less expensive venue for three different measures of cigarette price

\begin{tabular}{|c|c|c|c|c|c|c|c|c|c|c|c|}
\hline \multirow[b]{2}{*}{ Demographic characteristics } & \multirow[b]{2}{*}{$\mathbf{N}$} & \multirow[b]{2}{*}{$\mathbf{n}$} & \multicolumn{3}{|c|}{$\begin{array}{l}\text { Purchase from any cheaper } \\
\text { venue* }^{*}\end{array}$} & \multicolumn{3}{|c|}{$\begin{array}{l}\text { Smoke discount/generic or } \\
\text { use more couponst }\end{array}$} & \multicolumn{3}{|c|}{$\begin{array}{l}\text { Either use cheaper venue or } \\
\text { generics or more coupons }\end{array}$} \\
\hline & & & $\%$ & OR & $95 \% \mathrm{Cl}$ & $\%$ & OR & $95 \% \mathrm{Cl}$ & $\%$ & OR & $95 \% \mathrm{Cl}$ \\
\hline \multicolumn{12}{|l|}{ Price differential } \\
\hline 0 cents & 1529 & 248 & 16 & 1.0 & Referent & 46 & 1.0 & Referent & 53 & 1.0 & Referent \\
\hline $1-15$ cents & 404 & 125 & 31 & 2.6 & 2.0 to 3.5 & 51 & 1.3 & 1.0 to 1.7 & 63 & 1.8 & 1.4 to 2.4 \\
\hline $16-76$ cents & 1054 & 505 & 48 & $\overline{5.6}$ & 4.5 to 6.9 & 32 & $\overline{0.6}$ & 0.5 to 0.7 & 61 & $\overline{1.5}$ & 1.3 to 1.8 \\
\hline $77+$ cents & 609 & 352 & 58 & 8.0 & 6.2 to 10.3 & 45 & $\overline{0.9}$ & 0.7 to 1.2 & 71 & $\overline{2.2}$ & 1.8 to 2.8 \\
\hline \multicolumn{12}{|l|}{ Sex } \\
\hline Male & 1677 & 561 & 33 & 1.0 & Referent & 37 & 1.0 & Referent & 55 & 1.0 & Referent \\
\hline Female & 1919 & 669 & 35 & 1.2 & 1.0 to 1.4 & 47 & 1.6 & 1.4 to 1.9 & 63 & 1.6 & 1.4 to 1.9 \\
\hline \multicolumn{12}{|l|}{ Age in 1988} \\
\hline $25-34$ years & 1217 & 412 & 34 & 1.0 & Referent & 39 & 1.0 & Referent & 57 & 1.0 & Referent \\
\hline $35-44$ years & 1275 & 433 & 34 & 1.1 & 0.9 to 1.4 & 42 & 1.1 & 0.9 to 1.3 & 59 & 1.1 & 0.9 to 1.3 \\
\hline $45-54$ years & 710 & 243 & 34 & 1.2 & 0.9 to 1.5 & 46 & 1.2 & 1.0 to 1.6 & 62 & 1.2 & 1.0 to 1.5 \\
\hline $55-64$ years & 394 & 142 & 36 & 1.4 & 1.0 to 1.9 & 45 & 1.2 & 0.9 to 1.6 & 61 & 1.2 & 0.9 to 1.7 \\
\hline \multicolumn{12}{|l|}{ Race } \\
\hline White, non-Hispanic & 3139 & 1094 & 35 & 1.0 & Referent & 44 & 1.0 & Referent & 61 & 1.0 & Referent \\
\hline Black, non-Hispanic & 203 & 55 & 27 & 0.8 & 0.6 to 1.3 & 27 & 0.5 & 0.3 to 0.7 & 47 & 0.6 & 0.5 to 0.9 \\
\hline Hispanic & 177 & 55 & 31 & 0.7 & 0.4 to 1.0 & 30 & $\overline{0.8}$ & 0.6 to 1.2 & 49 & 0.7 & 0.5 to 1.0 \\
\hline Other & 76 & 26 & 34 & $\overline{1.8}$ & 1.0 to 3.2 & 35 & 0.6 & 0.3 to 1.1 & 53 & 1.0 & 0.6 to 1.6 \\
\hline \multicolumn{12}{|l|}{ Income in 2001} \\
\hline$<\$ 15000$ & 256 & 88 & 34 & 1.0 & Referent & 52 & 1.0 & Referent & 64 & 1.0 & Referent \\
\hline$\$ 15000-\$ 37500$ & 810 & 263 & 32 & 0.9 & 0.6 to 1.4 & 48 & 0.8 & 0.6 to 1.2 & 61 & 0.9 & 0.6 to 1.2 \\
\hline$\$ 37501-\$ 60000$ & 1087 & 374 & 34 & 1.2 & 0.8 to 1.7 & 45 & 0.7 & 0.5 to 1.0 & 61 & 0.9 & 0.7 to 1.3 \\
\hline$>\$ 60000$ & 1195 & 423 & 35 & 1.3 & 0.9 to 1.9 & 34 & 0.5 & 0.4 to 0.7 & 55 & 0.8 & 0.6 to 1.2 \\
\hline \multicolumn{12}{|l|}{ Number of cigs per day (2001) } \\
\hline$<5$ & 328 & 70 & 21 & 1.0 & Referent & 30 & 1.0 & Referent & 39 & 1.0 & Referent \\
\hline $5-14$ & 909 & 271 & 30 & 1.1 & 0.8 to 1.7 & 34 & 0.9 & 0.7 to 1.3 & 52 & 1.3 & 0.9 to 1.8 \\
\hline $15-24$ & 1529 & 564 & 37 & 1.4 & 1.0 to 2.1 & 44 & 1.3 & 0.9 to 1.9 & 64 & 1.8 & 1.3 to 2.6 \\
\hline $25-34$ & 474 & 199 & 42 & $\frac{1.4}{2.0}$ & 1.3 to 3.2 & 50 & 1.7 & 1.1 to 2.5 & 69 & $\frac{1.0}{2.4}$ & 1.6 to 3.5 \\
\hline$\geqslant 35$ & 345 & 123 & 36 & $\frac{.5}{1.6}$ & 1.0 to 2.7 & 54 & 2.1 & 1.3 to 3.2 & 66 & 2.4 & 1.6 to 3.6 \\
\hline \multicolumn{12}{|l|}{ Desire to quit (2001) } \\
\hline Not at all & 349 & 113 & 32 & 1.0 & Referent & 47 & 1.0 & Referent & 60 & 1.0 & Referent \\
\hline A little & 444 & 142 & 32 & 1.0 & 0.7 to 1.5 & 41 & 0.8 & 0.6 to 1.1 & 57 & 0.9 & 0.6 to 1.2 \\
\hline Somewhat & 1120 & 403 & 36 & 1.3 & 0.9 to 1.8 & 45 & 1.0 & 0.7 to 1.3 & 63 & 1.2 & 0.9 to 1.6 \\
\hline A lot & 1331 & 491 & 37 & 1.2 & 0.9 to 1.7 & 43 & 0.8 & 0.6 to 1.1 & 61 & 1.0 & 0.7 to 1.3 \\
\hline \multicolumn{12}{|l|}{ Number of past quit attempts } \\
\hline 0 & 1096 & 370 & 34 & 1.0 & Referent & 42 & 1.0 & Referent & 59 & 1.0 & Referent \\
\hline 1 & 721 & 270 & 37 & 1.1 & 0.9 to 1.4 & 40 & 0.9 & 0.7 to 1.2 & 59 & 1.0 & 0.8 to 1.3 \\
\hline $2+$ & 1733 & 579 & 33 & 0.9 & 0.7 to 1.1 & 43 & 1.2 & 1.0 to 1.5 & 60 & 1.1 & 0.9 to 1.4 \\
\hline \multicolumn{12}{|l|}{ Time to first cigarette (2001) } \\
\hline $61+\min$ & 621 & 159 & 26 & 1.0 & Referent & 31 & 1.0 & Referent & 44 & 1.0 & Referent \\
\hline $31-60$ mins & 622 & 200 & 32 & 1.2 & 0.9 to 1.6 & 39 & 1.1 & 0.9 to 1.5 & 57 & 1.2 & 0.9 to 1.6 \\
\hline $10-30$ mins & 1262 & 453 & 36 & 1.2 & 0.9 to 1.6 & 43 & 1.2 & 0.9 to 1.6 & 61 & 1.2 & 1.0 to 1.6 \\
\hline$<10$ mins & 1066 & 412 & 39 & 1.4 & 1.0 to 1.9 & 50 & 1.5 & 1.1 to 2.0 & 67 & 1.6 & 1.2 to 2.1 \\
\hline \multicolumn{12}{|l|}{ Pricing tier of current brand } \\
\hline Premium & 2416 & 0 & 33 & 1.0 & Referent & \multirow{2}{*}{\multicolumn{3}{|c|}{ Not included in this model }} & \multirow{2}{*}{\multicolumn{3}{|c|}{ Not included in this model }} \\
\hline Discount/generic & 964 & 0 & 37 & 1.3 & 1.1 to 1.6 & & & & & & \\
\hline \multicolumn{12}{|c|}{$\begin{array}{l}\text { Results are from logistic regression modelling the report of purchase of cigarettes from a cheaper venue while simultaneously controlling all variables presented in } \\
\text { the table. Underline odds ratios are significant at the } 5 \% \text { level. } \\
\text { "A response of "yes" to any of the questions: "In the last } 12 \text { months, did you purchase cigarettes over the Internet for your own use?"; "In the past } 12 \text { months, have } \\
\text { you or a friend or relative regularly purchased cigarettes for your own use on an Indian reservation?"; "In the past } 12 \text { months, have you or a friend or relative } \\
\text { regularly purchased cigarettes for your own use in another state?"; "In the past } 12 \text { months, have you or a friend or relative regularly purchased cigarettes for your } \\
\text { own use in another country?". } \\
\text { †Either use coupons to purchase cigarettes more frequently now than five years ago or smoked a discount/generic brand in } 2001 \text {. }\end{array}$} \\
\hline
\end{tabular}

As shown in table 3, an average of $59 \%$ of all current smokers in 2001 reported that they have used at least one of the listed strategies to obtain lower taxed cigarettes (community range $34-83 \%$ ). Thirty four per cent reported using one of the four less expensive venues for cigarette purchases regularly in the 12 months before the survey because these cigarettes were cheaper (community range 12-73\%). Travelling to another state was the most commonly reported strategy (average $25 \%$, range 9-66\%) followed by travelling to an Indian reservation (average $11 \%$, range $1-64 \%$ ). Twenty eight per cent reported smoking a discount/generic brand (range $7-43 \%$ ), and 18\% reported using coupons more often than five years ago (range 5-32\%).

Multivariate analysis of factors associated with the report of purchasing cigarettes from low or untaxed sources, use of discount/generic cigarettes, and discount coupons is shown in table 4. The strongest predictors of purchasing less expensive cigarettes were living within 40 miles of a place with a lower cigarette excise tax (that is, price differential to a nearby state or country was $>0$ cents), higher daily cigarette consumption, white, non-Hispanic race/ethnicity, and female sex, although some other differences are observed for each outcome presented in table 4.

Table 5 shows the distribution of the use of premium and discount/generic brands and smoking status in 1988, 1993, and 2001 from the longitudinal survey sample. Overall, $28 \%$ of the cohort of smokers in 1988 who were tracked in 1993 and 2001 reported use of a discount/generic cigarette in at least one the three interviews. Rates of switching to discount/ generics from premium cigarettes and vice versa were comparable. Among those smoking the same type of cigarette in 1988 and 1993, approximately 60\% were smoking the same type of cigarette in 2001,30\% had quit smoking, and 10\% had switched to a different cigarette type. 
Table 5 Distribution of the use of discount/generic cigarettes and smoking behaviour between 1988 and 2001 from the longitudinal survey $(n=5225)$

\begin{tabular}{lllrr}
\hline 1988 & 1993 & 2001 & \multicolumn{1}{l}{ n } & \multicolumn{1}{l}{$\%$} \\
\hline Generic & Generic & Generic & 115 & 2.2 \\
Generic & Generic & Premium & 20 & 0.4 \\
Generic & Generic & Quit & 58 & 1.1 \\
Generic & Premium & Generic & 7 & 0.1 \\
Generic & Premium & Premium & 28 & 0.5 \\
Generic & Premium & Quit & 5 & 0.1 \\
Generic & Quit & Generic & 4 & 0.1 \\
Generic & Quit & Premium & 8 & 0.2 \\
Generic & Quit & Quit & 60 & 1.1 \\
Premium & Generic & Generic & 350 & 6.7 \\
Premium & Generic & Premium & 194 & 3.7 \\
Premium & Generic & Quit & 226 & 4.3 \\
Premium & Premium & Generic & 324 & 6.2 \\
Premium & Premium & Premium & 1707 & 32.7 \\
Premium & Premium & Quit & 826 & 15.8 \\
Premium & Quit & Generic & 45 & 0.9 \\
Premium & Quit & Premium & 184 & 3.5 \\
Premium & Quit & Quit & 1064 & 20.4 \\
& & & 5225 & 100.0 \\
\hline
\end{tabular}

Selected results based on table above: $27.6 \%$ were discount/generic brand users in 1988, 1993, or $2001 ; 5.8 \%$ were discount/generic brand users in 1988; $18.4 \%$ were discount/generic brand users in 1993;

$16.2 \%$ were discount/generic brand users in 2001 .

Among those who were discount/generic brand users in 1988 and 1993 ( $n=193$ ): $59.6 \%$ were still discount/generic brand users in $2001 ; 30.0 \%$ quit smoking by $2001 ; 10.4 \%$ switched to premium brands in 2001 Among those who were premium brand users in 1988 and 1993 ( $n=2857$ ): $11.3 \%$ switched to discount/generic brands in $2001 ; 28.9 \%$ quit smoking by $2001 ; 59.7 \%$ were still premium users in 2001 .

\section{DISCUSSION}

Data from this study indicate that a large majority of smokers are utilising opportunities to purchase less expensive cigarettes by travelling to other states and Indian reservations or by using discount/generic cigarettes or discount coupons. The price differential from nearby locations with lower cigarette excise taxes was a strong predictor of this behaviour. This shift toward purchasing cheaper cigarettes may mitigate the influence of increase cigarette prices.

Price sensitive smokers are the ones most likely to change their smoking behaviour because of the increase in price; however, with the availability of cheaper cigarettes, they can avoid paying full price and some are able to continue smoking at the same or perhaps reduced level of consumption. Due to the trend for increasing cigarette excise taxes, ${ }^{20}$ purchasing cheaper cigarettes is a behaviour that will most likely increase over time.

The purchase of lower or untaxed cigarettes is strongly related to the proximity to less expensive locations. This finding is consistent with data from western New York, which is in close proximity to dozens of Indian owned tobacco outlets, that found that $67 \%$ of smokers reported their usual source of cigarettes is from an Indian reservation. ${ }^{12}$

Since the late 1980s, the use of discount/generic cigarettes has increased dramatically. Data from this study shows continued use of these products by a large percentage of the population. These products retail for about two thirds the cost of premium brand cigarettes and present opportunities for price sensitive smokers who may have quit otherwise in the face of higher prices to continue smoking. Consistent with previous studies, we found those with the lowest incomes and greater daily cigarette consumption to be most likely to switch to discount/generic cigarettes. ${ }^{4}{ }^{12}$ Those who reported purchasing cigarettes from less expensive venues by travelling or using the internet were also heavier smokers; however, lower income smokers were not more likely to report using these venues more frequently than wealthier

\section{What this paper adds}

Higher cigarette prices result in decreased cigarette consumption, but price sensitive smokers may seek lower priced or tax-free cigarette sources as a strategy to maintain their smoking behaviour. This price avoidance behaviour costs states excise tax money and dampens the health impact of higher cigarette prices; however, most of the econometric studies that assess the link between higher prices and decreased smoking have been conducted before the widespread availability of lower priced options or rely on aggregate data, which may miss these effects among individuals with greater accessibility to lower priced options.

This paper examines cigarette purchasing patterns of current smokers to determine the effects of cigarette price on their use of cheaper sources as well as their use of discount/ generic cigarettes and coupons. Findings indicate that most smokers are price sensitive and those with the greatest accessibility to lower priced products are more likely to engage in this behaviour, which may decrease future cessation efforts.

smokers. One explanation for this finding is that a minimum level of resources is required for a consumer to travel relatively long distances or to use the web to find better cigarette prices. A related interpretation is that most consumers are price sensitive; however, different consumers express this sensitivity in different ways. From a public health perspective, this implies that less expensive cigarette purchase options such as discount/genetic cigarettes and low/ untaxed cigarette sources affect a large majority of the population and that the availability of lower priced alternatives may mitigate the public health benefit of cigarette price increases.

In this study and others investigating use of the internet for cigarette purchases, the rates of use were low $^{3}$; however, purchase rates were higher in places that had high cigarette excise taxes such as New York State. However, the potential exists for internet tobacco sales to grow in the future. Between February and November 2000, the number of websites selling cigarettes increased by $70 \%{ }^{21}$

Several interventions have been discussed to reduce the low or untaxed cigarette purchases, which could be effective in reducing incentives to purchase lower taxed products; however, measures to reduce the purchase of less expensive cigarettes by limiting generic cigarettes, promotions, or couponing may be more difficult to implement. Effective June 2003, New York State passed a new law that makes it illegal for common mail carriers to deliver cigarettes to New York State addresses; however, the impact of this measure remains in question as the US Postal service is not directly covered under these regulations and this measure does not dissuade smokers from travelling to lower priced venues for face-to-face transactions. A second intervention is to begin enforcing the Jenkins Act, which requires cigarette retailers and/or purchasers to report all out-of-state transactions to the tax authorities in that state who can then collect taxes from the purchaser. While this measure does not address mail order sales, if well enforced, it has promise for removing incentives to travel to lower priced states. A third option is to raise the federal cigarette excise tax significantly to reduce relative pricing differentials across states and reservation borders and between premium and discount/generic pricing tiers.

The main strengths of this study are the large sample of smokers, the detail of the purchase patterns queried, and the geographic diversity of subjects from 20 communities in the 
USA. An important limitation is that these data are not representative of any particular population and cannot be extrapolated to reflect any particular community or state. Subjects included in this analysis were originally oversampled because they were heavy smokers and were between the ages of 25 and 64 years in 1988; therefore, this sample is older and smokes more cigarettes per day than a random population of smokers. Because of this, our observed estimates of low or untaxed cigarette purchase rates may overestimate what would be observed in the general population of smokers. A second issue is that a more detailed assessment of the frequency of purchasing cigarettes from less expensive sources, such as the percentage of all cigarettes smoked obtained from such sources, would be desirable from a policy viewpoint but was not available for this study.

In summary, we found that most smokers in this sample reported that they made efforts to obtain less expensive cigarettes, and this was more frequently reported among those subjects who lived relatively close to these less expensive purchase options and heavier smokers. This behaviour may decrease the health benefit of cigarette excise tax increases by giving price sensitive smokers who might have quit otherwise product options within their budget. Policies that reduce price differentials across cigarettes retail venues would likely reduce this behaviour and increase cessation.

\section{ACKNOWLEDGEMENTS}

This research is funded by the National Cancer Institute's State \& Community Tobacco Control Interventions Research Initiative by grant number R01 CA 86225.

\section{Authors' affiliations}

A Hyland, J E Baver, Q Li, S M Abrams, C Higbee, L Peppone,

K M Cummings, Department of Health Behavior, Roswell Park Cancer Institute, Buffalo, New York, USA

\section{REFERENCES}

1 The National Center for Tobacco-Free Kids. U.S. Cigarette company price increases, 1993-2002. 21 June 2002.

2 Chaloupka FJ, Cummings KM, Morley CP, et al. Tax, price and cigarette smoking: evidence from the tobacco documents and implications for tobacco company marketing strategies. Tobacco Control 2002;11(suppl I):i62-72.
3 Emery S, White MM, Gilpin EA, et al. Was there significant tax evasion after the 199950 cent per pack cigarette tax increase in California? Tobacco Control 2002;11:130-4.

4 Cummings $\mathrm{KM}$, Hyland $\mathrm{A}$, Lewit $\mathrm{E}$, et al. Use of discount cigarettes by smokers in 20 communities in the United States, 1988-1993. Tobacco Control 1997;6:S25-30.

5 United States General Accounting Office, testimony before the Senate Democratic Task Force on Tobacco: Cigarette smuggling, Information on interstate and US-Canadian activity. http://www.heartland.org/pdf/ $80212 b . p d f$.

6 Gruber J, Sen A, Stabile M. Estimating price elasticities when there is smuggling: the sensitivity of smoking to price in Canada. J Health Economics 2003;22:821-42

7 Sung HY, Hu TW, Keeler TE. Cigarette taxation and demand. An Empirical Model Contemporary Economic Policy 1994;12(7):94-100.

8 Yurekli AA, Zhang P. The impact of clean indoor-air laws and cigarette smuggling on demand for cigarettes. an empirical model. Health Economics 2000;9:159-70.

9 Merriman D. Cigarette smuggling does not reduce the public health benefits of cigarette taxes. Applied Economics Letters 2002;9:493-6.

10 Hrywna M, Delnevo CD, Staniewska D. Prevalence and correlates of internet cigarette purchasing among adult smokers in New Jersey. Tobacco Control 2004; 13:296-300.

11 Hyland A, Higbee C, Baver JE, et al. Cigarette purchasing behaviors when prices are high. Journal of Public Health Management and Practice 2004; 10:497-500.

12 Cavin SW, Pierce JP. Low-cost cigarettes and smoking behavior in California, 1990-1993. Am J Prev Med 1996;12:17-21.

13 Lewit EM, Coate D, Grossman M. The effects of government regulation on teenage smoking. Journal of Law and Economics 1981;24:545-69.

14 Lewit EM. Coate D. The potential for using excise taxes to reduce smoking. $J$ Health Economics 1982;1:121-45.

15 COMMIT Research Group. Community intervention trial for smoking cessation (COMMIT): summary of design and intervention. J N t l Cancer Inst 1991:83:1620-8.

16 National Cancer Institute. Smoking and tobacco control monograph number 6. Community-based intervention for smokers: the COMMIT field experience, US Department of Health and Human Services. Public Health Service. National Institutes of Health. Nation Cancer Institute. NIH Publication no. 95, 4028; 1995.

17 COMMIT. Community intervention trial for smoking cessation (COMMIT): I. cohort results from a four-year community intervention. Am J Public Health 1995:85: 183-92.

18 Centers for Disease Control and Prevention. State tobacco activities tracking and evaluation system. Bethesda, Maryland: Office on Smoking and Health, CDC, http://www2.cdc.gov/nccdphp/osh/state/ rpt leg display.asp?rpt id $=\mathrm{L} 11$ \&subject type $=$ excise tax cents per_pack.

19 The Maxwell Report, February 2002. Year 2001 \& fourth quarter 2001 sales estimates for the cigarette industry.

20 The National Center for Tobacco-Free Kids. U.S. cigarette company price increases 1993-2002. The National Center for Tobacco-Free Kids. 21 June 2002. http://tobaccofreekids.com/research/factsheets/pdf/0091.pdf.

21 Bryant JA, Cody MJ, Murphy ST. Online sales: profit without question. Tobacco Control 2002;11:226-7.

\section{The Lighter Side}
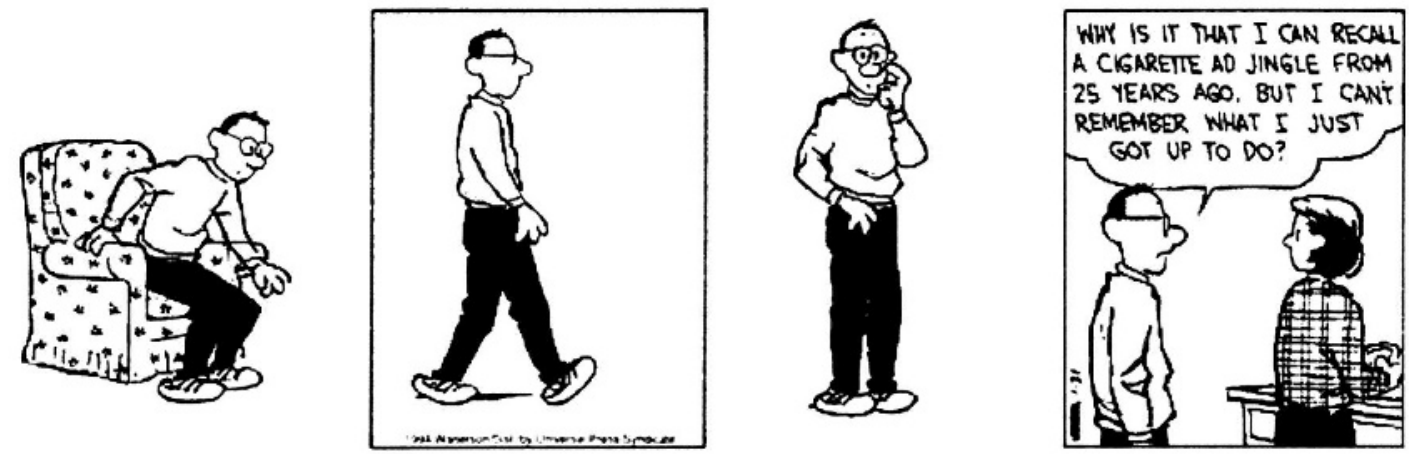

(c) Calvin and Hobbes by Bill Watterson. Universal Press Syndicate. 